Article

\title{
Human-Environment System Boundaries: A Case Study of the Honghe Hani Rice Terraces as a World Heritage Cultural Landscape
}

\author{
Honglian Hua ${ }^{1,2}$ and Shangyi Zhou ${ }^{1, *}$
}

1 School of Geography, Beijing Normal University, Beijing 100875, China;

E-Mail: huahonglian@mail.bnu.edu.cn

2 School of Tourism and Geography, Yunnan Normal University, Kunming 650500, China

* Author to whom correspondence should be addressed; E-Mail: shangyizhou @ bnu.edu.cn; Tel.: +86-139-1002-0509.

Academic Editor: Marc A. Rosen

Received: 31 March 2015 / Accepted: 31 July 2015 / Published: 7 August 2015

\begin{abstract}
Any World Heritage Cultural Landscape requires a clear boundary for administration. One of the administrative goals is sustainability. There is no widely identified way to demarcate the boundary of a World Heritage Cultural Landscape. This paper aims to explore a methodology framework to provide a holistic perspective for demarcating boundaries for a World Heritage Cultural Landscape. Honghe Hani Rice Terraces (HHRT) in Yunnan Province is a new World Heritage Cultural Landscape in China. We use it as a research area to illustrate the methodology framework. The framework of methodology is constructed based on four scales of a human-environment system identified by Anne Buttimer. It is used to describe the level of the sustainability of local economy, social organization, natural environment and people's understanding of the human-environment. Four types of boundaries were investigated in this area. They are the boundary of Malizhai River Basin, the boundary of local water-allocation organization, the boundary of the economic network and the perceptual boundary of the human-environment system. With a comprehensive perspective, we integrated the four types of boundaries to judge the boundary of the core area of HHRT by three criteria, they are: Environmental sustainability, social justice, and the ability to create a new human-environment system. We conclude that some parts of the boundary of the core area of HHRT do not fit the criteria of sustainable development.
\end{abstract}


Keywords: world heritage cultural landscape; boundary; human-environment system; Honghe Hani Rice Terraces

\section{Introduction}

Cultural landscapes represent combined works of nature and humankind that express a long and intimate relationship between people and their natural environment. In the 1990s, UNESCO began listing cultural landscapes that had universal significance as a new category of World Heritage. The decision was meant to encourage the protection of cultural landscapes and the human-environment relationship patterns reflected in them [1]. The Operational Guidelines for the implementation of the World Heritage Convention state that the legal protections of a cultural landscape are to designate a protection zone, with a boundary that should be drawn to ensure the full expression of the landscape's outstanding universal value and the integrity and/or authenticity of the property [2]. What this article discusses is how to define proper boundaries of a cultural landscape protection area for sustainable development.

The term cultural landscape, however, is complex conceptually, and as yet it has no generally accepted definition, making it difficult to ascertain what constitutes the landscape to be protected and how to create an appropriate boundary. In contrast, present approaches to define the boundary of cultural landscape properties can be, and are, very uncertain and simplistic. As a result, some properties have been threatened because of unreasonable boundary demarcations [3]. For instance, in the World Heritage Sites of Borobudur Temple Compounds (Indonesia) and Angkor (Cambodia), the boundaries of the core and buffer zones are to be designed as fixed-distance areas that vary in terms of the severity of land-use restrictions [4,5]. However, this mapping of fixed-distance measurements to identify a standardized core and buffer zone does not adequately recognize complex land-use patterns or pre-existing landscapes, or reflect residents' daily experiences and perceptions of their surrounding environment. The result is uncertain land use and an erosion of heritage values [6,7]. The Rice Terraces of the Philippine Cordilleras were listed as a World Heritage Cultural Landscape in 1995, but, this was later reclassified to the World Heritage in Danger List in 2001 because of the deterioration of the terraces [8]. The boundaries of the site were simply delineated based on the boundaries of the municipalities and some villages [9,10]. In fact, however, these villages do not exist in isolation, but are tied to other adjacent villages for activities such as irrigation and resource management. The designated boundary of the sites thus did not conform to the perception of local people, and narrowed the protection horizon and the restoration measures [11].

Most cultural landscapes develop based on changes in the human-environment system. Maintaining the system protects the cultural landscape. In most locations, the human-environment system corresponds to a certain geographic range [12,13], within which local people obtain appropriate resources and create a stable social organization to allocate natural resources and cope with environmental pressure and disasters. If the human-environment system is destroyed, the sustainability of the cultural landscape is threatened [14-16]. Determining the boundary of the human-environment system is thus key to maintaining the sustainable development of a cultural landscape. 
The identification of the boundaries of a human-environment system has been a major focus of geographical studies. Manson suggested that finding the boundary requires the consideration of many aspects of nature, society and economy [17]. Buttimer asserted that the scale of a human-environment system is formed in the process of economic and social activities. A human-environment system can be classified as having four types of scales: Administratively-defined scales, functionally-defined scales, perceptually-defined scales and naturally-defined scales [18]. The four scales provide a holistic perspective from which to analyze the boundary of a human-environment system. However, the term "scale" includes a complex array of meanings, and it has proven difficult to measure in objective spatio-temporal terms. The construction of a methodology framework based on the four "scale" types, is thus needed to identify approaches for defining the boundary of a human-environment system.

In the Asia-Pacific region, rice terraces constitute a typical cultural landscape. The protection of this kind of landscape is important for maintaining the diversity of a human-environment system. The "Honghe Hani Rice Terraces" (HHRT) in China were designated a World Heritage Cultural Landscape in 2013. The site consists of a spectacular rice-terrace landscape created by the Hani people on the slope of Ailao Mountains. As early as 2001, in order to protect the HHRT, the local government delineated the boundary of the HHRT reserve. Over more than ten subsequent years, the boundaries of the protection area were changed several times in the application process to become a World Heritage Site. In view of the complexity of demarcating a boundary for protecting a cultural landscape, at the HHRT as well as at the Rice Terraces of the Philippine Cordilleras and Angkor, it is clearly important to evaluate whether the existing core area boundary of the HHRT site is appropriate and beneficial to its sustainable protection as a World Heritage Site. This research will construct a methodology framework for identifying the boundaries of a human-environment system, and consider the World Heritage Site of HHRT as a case study to implement this framework for determining the boundary and to evaluate the existing boundary.

\section{Methodology}

\subsection{Theoretical Basis}

According to Buttimer, the scales of a human-environment system are multi-dimensional and change with the dynamics of economy, society and policy [19]. There are four kinds of scale to describe the dimensions of a human-environment system, where each corresponds four types of "spatial reach". "Administratively-defined scales" are politically defined scales of administrative reach, through which social and political functions are normally processed. "Functionally-defined scales" are industrially defined scales of functional reach, such as the radius of a manufacturing system or service network, which is made up of nodally organized spaces. From a "bottom-up" perspective, functional reach involves access to employment, retail and other aspects of everyday social space that have considerable influence on the maintenance of social vitality. "Perceptually-defined scales" are scales of place that people belong to and can identify typically the well-known and traversed area from home through a neighborhood. "Naturally-defined scales" are spatial scales of a physical geography region, which mix several aspects such as land-us, natural resources and ecological systems [20]. 
In terms of Buttimer's definition of these four types of scale, a human-environment system's boundaries can be defined in four ways: Administrative range, natural range, perceptual range and functional range. Functional range can be divided into two subtypes: The economical network, which is a nodally organized space, and the social space, which maintains social vitality, allows us to use both an economic network boundary and a social organization boundary to define the functional range. The four types of boundaries provide a holistic means to describe the human-environment system. However, Buttimer did not provide approaches to demarcate the boundaries. Moreover, she did not propose some criteria to judge what kind of boundary is appropriate for the sustainability of a human-environment system. These are common problems in the process of designating boundaries for a protection area, and are what we hope to address by constructing a methodology framework for identifying the boundary of a human-environment system. It should be noted that, for many World Heritage Sites, the administrative boundary is determined based on the other three boundary types, so this discussion will not analyze the administrative boundary, but only the other three types.

\subsection{Methods for Identifying Boundaries}

A number of ways to identify the boundary of a physical geography region of a human-environment system have been described in the literature. Vallés studied the indicators of landscape unit delineation and identified the main trends in selecting indicators based on 29 planning programs for demarcating the boundary of cultural landscapes in Spain. The result shows that Spanish professionals prefer to use geomorphology as a key element in landscape-unit delineation [21]. Wiens pointed out that boundaries occur when structural or functional properties of ecological systems change discontinuously or nonmonotonically in space or time. Boundary can therefore be characterized by the rate of change in variables of interest in space or time. Traditionally, ecologists have used boundaries such as watersheds to define units [22]. Lech studied the agricultural landscape of western Poland, finding that the windbreak belt serves the function of limiting the circulation of materials. He suggested that the barriers of material circulation can be used as the boundary of an agricultural landscape [23]. Current literature makes clear that geomorphology, for example, watersheds, and barriers of material circulation are most often used to identify the boundary of a physical geography region within a human-environment system.

The range of the economic network of a human-environment system relates to the range of production and marketing. O'Reilly analyzed the economic network of Slieveardagh in Tipperary County, Ireland. The local economy of Slieveardagh is based on the dairy industry and ranching; traditionally, the production and services take place at the parish level. With the influence of regional integration of the dairy industry because of the European Union (EU) dairy market, the production of dairy products and the distance needed to transport them grew. The range of resource usage and production moved beyond the parish level [24]. The case illustrates that the range of a human-environment system changes with the expanding of economic activities, and growth in the range of production and marketing is the primary contributor to the change. The boundary of production and marketing can thus be used as the boundary of an economic network.

For most cultural landscapes, especially the "organically evolved landscapes", a social organization forms from the interaction of people and their environment, forming a core that supports the sustainable development of the human-environment system. Social organization can typically be observed through 
cooperative activities. We can thus use the boundary of cooperative activities as the boundary of social organization. Lansing et al. study of the Balinese terraced landscape described the relationship between agricultural production and social organization. The studies show that the social organization of "water temple congregations" emerged out of a "need to balance multiple agro-ecological concerns in a crowded landscape of terraced rice fields," and the water temple network corresponded with a certain spatial range [25,26]. Acabado described similar elements of the Balinese terraced landscape, in the Ifugao terrace systems where the expansion of terraced fields placed pressure on land and water and resulted in pest increase. These pressures provided the impetus for villages sharing a water source and whose fields are contiguous to work together and pool resources. Usually, the villages were organized and formed an informal group based on the kinship system in the same watershed [27]. The expanse of these villages is the range of the social-organization network.

The spatial range of a human-environment system results from the process of perception of one's environment, and is customarily experienced when using natural resources. Studies of the human-environment systems of nomadic areas provide examples of this [28-31]. Beyene studied nomadic residents in Eastern Ethiopia and found that the local residents experienced the declining productivity of their local pastureland and a shift in the balance of the original human-environment relationship between stock farming and the environment. In order to accommodate these changes, the herdsmen would negotiate to find a new range for pastoral use to ensure the sustainable development of their animal husbandry. The identifying criteria relied on their experience and perception of resources, such as water sources, camping points and grassland. Thom completed a survey of the Coast Salish people who live in the border area of British Columbia, Canada and the US state of Washington. He found the perception of the territory of Coast Salish was not based on a country's border, but resulted from their understanding of the allocation of natural resources, their shared area of production and the kinship network [32]. Wainwright and Bryan studied the Awas Tingn people in eastern Nicaragua. They found that the understanding of territory for the Awas Tingn was closely related to their living patterns and customs. The Awas Tingn believed that any area that had a close long-term connection to their life and their conventional habitual behaviors were part of their territory [33]. The spatial sense of a long-term living experience is thus seen to be significant in maintaining the sustainable development of a human-environment system.

\subsection{The Criteria for Judging a Boundary of a Cultural Landscape}

The purpose of protecting a cultural landscape is to maintain its capacity for sustainable development. Although there has been little research directly addressing the relationship of a boundary to the protection of a sustainable cultural landscape, we can learn from some cases in which demarcating a protection zone leads to different impacts on a cultural landscape and can then summarize the criteria for judging which boundary is most appropriate.

The first criteria is social justice. The term refers to the inclusion of local people's needs and interests in delimiting a boundary for protection areas, which is essential both to promote the well-being of local populations and to ensure the sustainability of the cultural landscape [34,35]. Political ecology studies have pointed out that the designation of geographical areas as relevant for conservation results from a process of internal territorialization, or the act of excluding or including people within particular 
geographic boundaries and from the restrictions on activities within the territory [36-38]. If the chosen boundary does not represent the equitable treatment of local people's needs and interests, the protection area will lose local support [39]. As just one example among many [40,41], Russell and Jambrecina describe the declaration of the Tasmanian Wilderness World Heritage Area and its exclusion of the traditional practices of local people. As a result, the community experienced a continual erosion of rights and resented the Parks and Wildlife Service. Under pressure from community protest, managers were tasked with re-planning the heritage site to better understand community needs [42].

The second criteria is environmental sustainability, meaning that the boundary of the preservation area should be of an appropriate size and extent to allow for the sustainable development of the human-environment system. This issue has recently become a growing concern of geographers and ecologists. Woodley points out that most protected areas are too small to allow large-scale ecological processes or to protect viable populations of many organisms, especially large vertebrates and carnivores, the protected area boundaries should provide an appropriate range to maintain the sustainable development of natural environment and adjust the entry of threats [43]. Noss considered that boundaries may be able to protect the ecosystem from outside environment challenges, he suggests that the boundary of a protected area must be large enough and adjustable, the managers of reserves must demonstrate the flexibility to adjust the range of land-management activities [44]. Schonewald-Cox found that the boundary of a protected area is administratively derived and physically intangible, and is usually delineated by borders that reflect pre-existing land ownership. This may be set down irrespective of any natural ecological edges associated with a reserve. Arguably, a human derived boundary will destroy the integrity of the ecology system [45].

The third criteria is the ability to create a new organization for a human-environment system. This means that the boundary of preservation area should include the spatial and physical results of the constructing process of heritage scale. Richards suggests that the protection of cultural landscapes has been shifting from the conservation of isolated monuments to the perception heritage as inextricably linked to the surrounding areas [46]. Traditionally, the scales of heritage spaces were divided into two types: Heritage and non-heritage. The scale of heritage serves as a monumental space that feeds the development of the surrounding area, the surrounding area refers to the scale of non-heritage that supports the practical and functional uses of heritage space. Heritage can be seen as serving a functional purpose as a cultural and economic resource [47]. Using heritage resources to improve the quality of life for the host population is one successful way to ensure the preservation of heritage sites [48]. In the process of developing and protecting this resource, heritage scales are established by diverse stakeholders through socially and politically constructed relationships between heritage sites and surrounding areas. The concept of scale is thus not a pre-defined hierarchical system [49,50], but are sets of relations [51,52] that are continually produced and reproduced [53]. With the increasing functional connections between the heritage site and its surroundings, the scale of the site is constructed, expanded and transformed. With the expanding influence of heritage, the boundaries and relationships between its scales should be redrawn so that boundaries should reflect the process of scale construction between heritage sites and their surroundings. Here, the case of Angkor is instructive. The town of Siem Reap, in the area surrounding Angkor, has undergone a sharp transformation since the inscription of Angkor onto the World Heritage List [54]. The relationship between Siem Reap and Angkor was one in which Siem Reap, with its modern urban landscape, had a vital role in providing services that the heritage area was 
unable to supply due to restrictions on aesthetics and activities. The functional connection between Siem Reap and Angkor as a heritage site changed the stakeholders' perception of the boundary between the heritage scale and non-heritage scale. Butland's study illustrated that the scale of a heritage space and non-heritage space is constructed and changes depending on stakeholders' values. The boundary of a heritage space should be redrawn based on the perceptions and the behaviors of diverse stakeholders [55].

\subsection{Methodology Framework}

Regional geography emphasizes a holistic analysis of the human-environment system. This means that all the dimensions of the human-environment system should be identified. Based on Buttimer's four scale types, the methods for identifying the boundary and the criteria for judging a boundary described above, we constructed a methodology framework for identifying the boundary of a cultural landscape, shown in Figure 1. The framework comprises three steps and a corresponding methodology. First, we identify boundaries of the human-environment system. To do this, we draw four boundary categories based on each of four methods. Specifically, we use the range of geomorphic units to demarcate a boundary of the physicalgeography region, the range of production and marketing to demarcate an economic-network boundary, the geographic range of social organization to demarcate a social-organization boundary and the range of perceptions of human-environment system to demarcate a perceptual boundary. Second, these three criteria are used to evaluate the function of each boundary. Finally, the evaluation results are used to determine the appropriate boundary of a World Heritage cultural landscape. We will use the case of the World Heritage HHRT site to illustrate the framework in later sections of this paper.

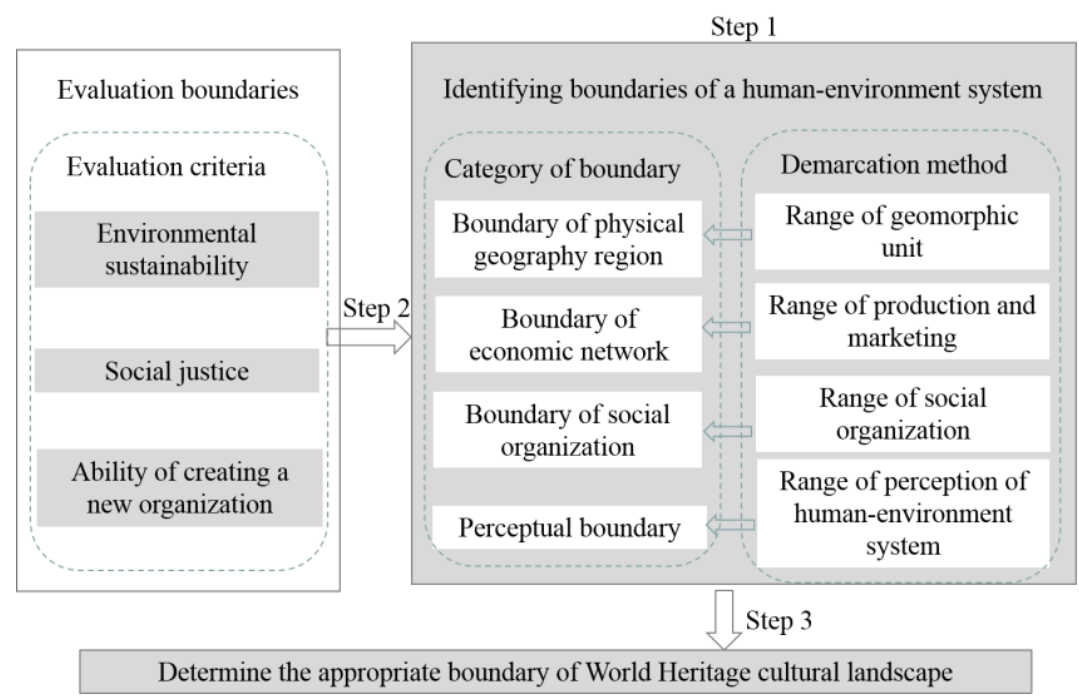

Figure 1. Methodology framework for identifying the boundary of a cultural landscape.

\section{Study Area}

\subsection{Overview}

The Honghe Hani Rice Terraces are widely distributed throughout the southern bank of the Honghe River and the southern piedmont of the Ailao Mountains in southern Yunnan, a southwest border 
province of China. With total land coverage of 11,000 square kilometers, the area of rice terraces in this region is about 54,700 hectares. The Honghe Hani Rice Terraces are located primarily in four counties, including Yuanyang, Honghe, Lvchun and Jinping. The World Heritage Site of HHRT is located in Yuanyang County, which has a total area of 46,100 hectares, of which 8866.82 hectares are rice terrace fields (see Figure 2). There are four rivers passing through the protected area, including the Malizhai, Dawazhe, Geta and Amengkong Rivers. Considering the large size of the heritage site, we selected villages within the basin of the Malizha River, one of the site's major rivers, as the focus of our research in order to analyze the boundaries of the villages' human-environment relationship. The whole basin of the Malizhai River contains nine administrative villages and some hamlets that have an additional three administrative villages. The villages are Luopu, Zhulu, Malizhai, Quanfuzhuang, Tuguozhai, Shuipulong, Xinjie, Anfen, Baojiaoling, Shitouzhai, Gaocheng and Shengcun Village. Residents within the Zhulu, Malizhai and Quanfuzhuang villages are all Hani nationality, while residents of both Yi and Hani nationality live in Luopu, Xinjie, Shuipulong and Tuguozai. The residents of Anfen are of Yi nationality. Residents of both Yi and Zhuang nationality live in Bajiaoling.

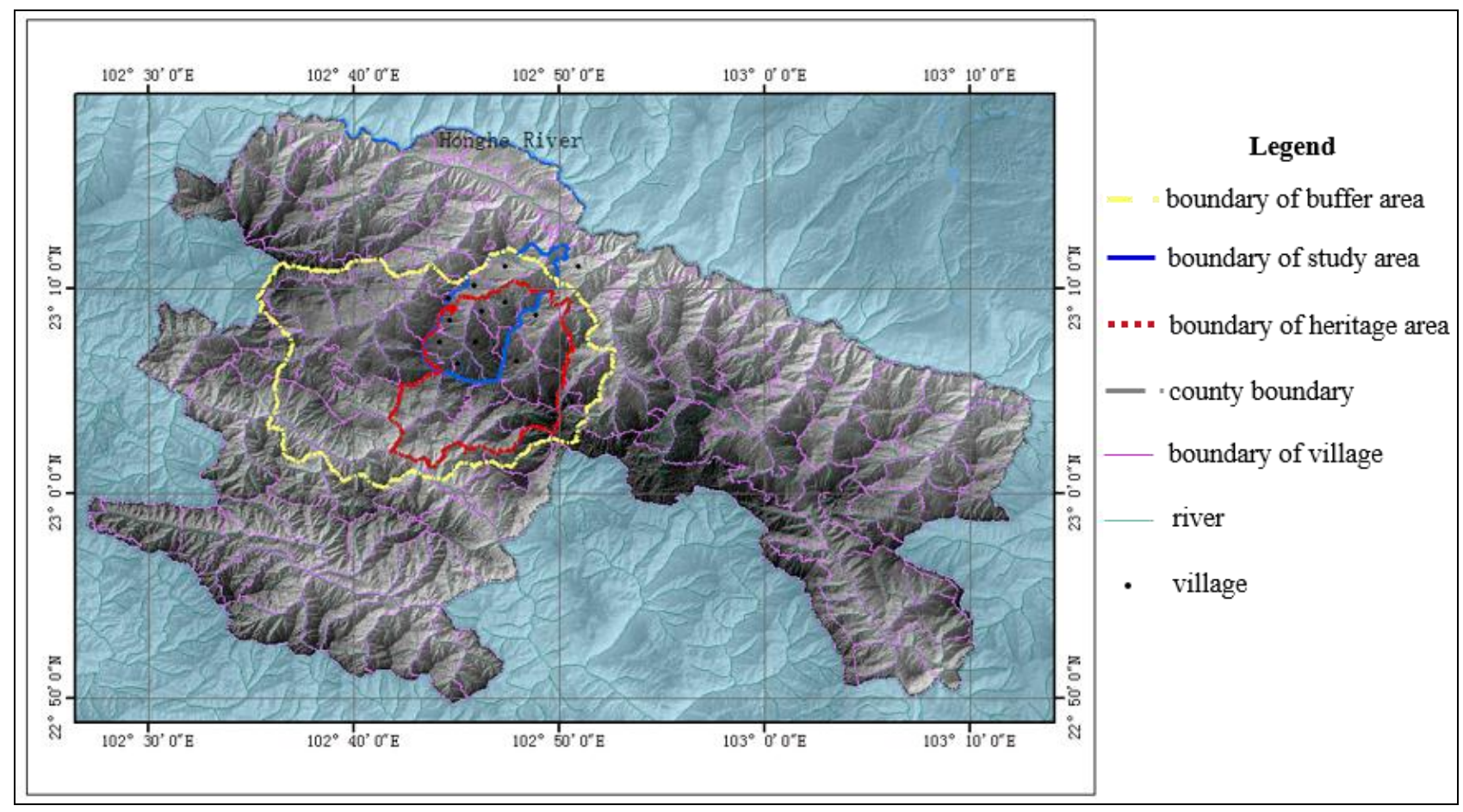

Figure 2. Location of study area.

\subsection{The Human-Environment System in HHRT}

It is widely accepted in Chinese scholarship that "the Hani" are descendants of the primitive di-qiang, a nomadic people originating from the Qinghai-Tibet Plateaus in northwest China [56-58]. As recorded in a member of Chinese historical texts, in the 1st Century A.D., Hani ancestors moved into the Ailao Mountains of the Honghe River Valley and started the "slash-and-burn" (swidden) agriculture of upland dry grains. During the Chinese Tang Dynasty (6th Century A.D.), the "cultural transformations" from dry-grain swidden agriculture to upland wet-rice cultivation through the adoption of the water culture of other ethnic groups who practice wet-rice agriculture in lower-altitude valleys, allowed the Hani to 
transplant low-land wet-rice farming to steep mountainsides, creating terraced fields and upland irrigation, and eventually replacing their original dry-grain swidden agriculture [59]. In the Ming Dynasty (1368-1644), Hani-cultivated rice terraces were recorded as one of seven types of Chinese farmlands in the renowned Encyclopedia of Agronomy. Later, in the Qing Dynasty (1616-1911), more in-depth descriptions of the spectacular rice-terrace fields cultivated by the Hani appeared in Chinese local chronicles. Thus, over at least 1300 years, the cultivation of wet-rice in upland terraced fields has been maintained by the Hani as their main subsistence product in south Yunnan [60]. The relationship between the Hani people and the environment is mainly characterized by this livelihood, and its social system and cultural ideology has been created from the interaction between people and their natural environment. These characteristics can be illustrated by three types of relationships.

First is the relationship between environment and farming. HHRT is located in rolling mid-mountain zones. The dramatic differences in elevation due to the high mountains and deep valleys create a diversified, vertical climate. In order to meet their livelihood demands, the Hani have utilized these natural conditions to develop an ecological system, known as the "Forest, Villages, Rice Terraces and Water System". In the system, forest is present at the highest point. When rainfall ends, many rivers and pools emerge in the forest to create a natural water source. The mid-mountain areas with moderate climate are ideal for dwelling. The Hani constructed houses on the sunny, exposed sites in the mid-mountain areas. The whole mid-mountain area, from the boundaries of villages to the valleys, is filled with rice terraces. As the lifeblood of terrace farming, water links forest, village and rice terrace into one integral whole: The water, retained by the forest, is drained to ditches and flows into the village and rice terraces to meet the demand for irrigation. Finally, it gathers in the valley and evaporates, generating rain that is stored in the forest again, forming a circular ecological system. On the basis of this system, sustainable terraced farming was established in the Ailao Mountains.

Second is the relationship between social organization and farming. Water is the most critical element in terraced farming in mountainous regions. Suitable space in which to create a terraced field, while limited, is also critical. These two elements become more critical problems with the area's growing population. In order to produce sufficient rice to meet the demand of the growing population and to guarantee the fair allocation of water resources, the residents established a village separation strategy and a water allocation system. The main objective of the village separation strategy is to deal with the limitation of rice terraces and water resources. With the increasing population, the original rice terraces could not meet demand, which led to the need for new rice terraces at a distance that are be less convenient and require higher labor intensity. To address this, some residents who are related through kinship, volunteered to move from their original village (mother village) to a new location, creating a sub-village. In order to mark the cognatic kinship and geographical relationship between the mother village and sub-village, Hani residents adopted a naming method called "connecting the name of the new sub-village with the name of the mother village" [61,62]. In order to share irrigated water, the Hani people also established a unique water-allocation organization to guarantee the efficient management and equal distribution of water resources, which was implemented between the families in one village, the mother villages and sub-villages, and upstream and downstream villages. In order to allocate water equally and effectively, the Hani people built intricate ditches that link each plot of rice terrace to villages. Each village has one ditch leader to take charge of the management of the village's ditches and 
the coordination with other villages for the allocation of water. The water allocation organization is the most typical example of the Hani's social organization.

Third is the relationship between the environment, livelihood, social organization and ideology. The residents gradually established a unique spatial recognition of the balance between forest, village, rice terraces and water in their long-term interactions with the environment. The Hani people believe that the "rice terrace is the lifeblood of the human being, water is the lifeblood of rice terraces and the tree is the lifeblood of water." They have completely integrated this recognition into their daily life. During major festivals and worship ceremonies, Migu (the spiritual specialist, authority and core of the social organization) would organize all the villagers to worship the forest, water source and rice terraces to emphasize their importance and strengthen the spatial recognition of the village $[63,64]$. When it came to planning festivals and worship activities among the kinship villages, the order of the villages to celebrate the festival is determined according to the separation process of the villages. This serves to strengthen the geographical identity of the villages. Another important aspect of the life of the Hani people is the funeral ceremony, which also serves to strengthen kinship and geographical identity. During the funeral ceremony, Mupi (the village priest, another core of the social organization), would read prayers to send the dead to embrace their ancestors and narrate the history and settlement process of their ancestors, repeating the story of the village-separation process.

Above all, it is their interactions with the environment that have led the Hani people to develop a livelihood pattern of rice-terrace farming in mountainous areas. The water-allocation organization is the core of this livelihood pattern and is important for the sustainable development of the human-environment system of the HHRT. Along with the gradual decline in available space and under the influence of the administrative division, the village separation strategy disappeared. In contrast, the water allocation organization remains in Hani' society today. On the basis of such a livelihood pattern and social organization, the Hani people developed a unique identification with the natural environment and kinship that corresponds to a certain geographical space. These ideologies in turn play an active role guiding environmental practices.

The World Heritage Site of HHRT is a typical representative of the human-environment system described above. With the development of heritage tourism, some local residents also participate in tourist activities. Although rice-terrace farming is still the main livelihood and the water-allocation organization has been preserved, the influx of tourists imposes continuous pressure on the natural environment and brings new challenges to the traditional resource allocation. Along with the increasing complexity of the human-environment system in the HHRT, the balance between protection and development has become a priority for its sustainable development.

\section{Boundaries of the HHRT Human-Environment System}

According to the methodology framework for identifying the boundary of a human-environment system, we should demarcate four types of the boundaries of the human-environment system of HHRT. They are: The boundary of the physical geography region, the boundary of the economic network, the boundary of social organization, and the perceptual boundary of the local human-environment system. Among these, social organization exists at different social levels, but the water-allocation organization is 
more typical and is key to maintaining the sustainable development of rice terraces. We thus used the boundary of water-allocation organization to substitute for the social-organization boundary.

\subsection{Boundary of Physical Geography Region}

The boundary of the physical geography region is the basis for the sustainable development of the human-environment system of HHRT. We used the boundary of watersheds to demarcate the natural boundary. There are many branches in the downstream region of Honghe River, and the basin of each branch controls the direction of water flow and material circulation. The water is shared between the villages in the same watershed. From an ecological view, landscape boundaries have the following features: Since the vector movement of materials and energy would be influenced by boundaries, they are located at points with sudden transmission changes in velocity and in magnitude of the energy flow and nutrient materials $[65,66]$. For the HHRT region, the basin boundary is both the place where the direction of the water flow changes, and it determines the flow direction of soil and the main migration direction of microbes. In this physical geographical region, the forest located at the mountaintop, stretches from the mountaintop to the valley, in the order of the village and the rice-terraces. Water originates in the forest, then flows into the villages and rice-terraces, and finally flows into rivers after repeated utilization in the rice-terraces [67]. The basin boundary is the border at which point the flow direction for water, soil and microbes changes. Therefore, the watersheds boundary could be used as the boundary of the physical geography region of the human-environment system of the HHRT. In the Malizhai Basin, there are nine villages and some separate hamlets that are located in the other three villages. In this basin, the rice terraces are distributed in plots as a whole, and the boundary of the Malizhai Basin nearly corresponds to the boundary of the physical geography region for these rice terraces. In the bottom of the Honghe River valley, however, where the climate is arid and hot, the rice terraces have disappeared. If the arid and hot region is moved, the boundary of the remaining range of the Malizhai River Basin can be viewed as the boundary of the physical geography region for HHRT. Usually, the distribution range for HHRT in this region is at an altitude of over $300 \mathrm{~m}$. At lower altitudes, the region belongs to the Dai people, who have a human-environment system that is totally different from that of Hani' [68]. We therefore first draw the specific boundary of the Malizhai River Basin based on the topographical map. Next, based on the information of altitude, agricultural pattern, land-use, livelihood of the Dai villages [69], we move these hamlets away from the range of the Malizhai River Basin. The boundary for the remaining range is the boundary of the physical geography region. (See Figure 3). We collected the information on the website of local government [69], which has the information of agricultural pattern, land-use and livelihood for each village. In addition, then we confirmed all of these information by fieldwork.

\subsection{Boundary of Water-Allocation Organization}

The organization of water-allocation is key to understanding social organization and is the basis on which the sustainable development of rice terraces is maintained. Allocation of water is determined based on shared ditches and negotiation among villages. We interviewed eight ditch leaders, four of they came from the upstream villages, and the other four came from downstream villages. They showed us the area of water allocation organization in the Malizhai River Basin. When we conducted our field 
work, we found intricate ditches built on the b ranches of the Malizhai River to irrigate the rice terraces. These ditches connect into a network that connects all villages together. For instance, the ditches on the boundaries of Zhulu, Luopu and Malizhai connect these three villages into one integral part. There are also cross-border ditches between Luopu and Shitouzai, Malizhai, Quanfuzhuang and Shengcun, Quanfuzhuang and Tuguozhai, Tuguozhai and Shuibulong, Shuibulong and Xinjie, Xinjie and Anfenzhai, and Anfenzhai and Bajiaoling, which connect these villages into one integral unit from which water is allocated collectively. The villages and rice terraces that are connected by the ditches appear to be located at different points in the upstream and downstream. The ditch leader of Quanfuzhuang Village, who is the fourth generation ditch leader in his family, told us that these ditches were built by the villages in the same watershed. The kinship and friendship among the villages ensure that they allocate water in such a way to support mutual livelihoods. However, in order to guarantee the equal utilization and distribution of water resources, these villages established a rigorous water-allocation system. The system clearly regulated the water consumption of each village. They often carved water gaps of different sizes at the shared ditches, with each gap corresponding to one village, and then the water would be allocated conventionally based on these water gaps. The water allocated to each village is the result of negotiation among the villages. The administrative village is typically the negotiation unit. This results is a water allocation boundary that corresponds to the administrative boundary of the villages within the Malizhai River Basin. Because the Malizhai River Basin contains nine administrative villages and some separate hamlet with three additional administrative villages, the periphery of these twelve administrative villages is the boundary of water-allocation organization. (See Figure 3).

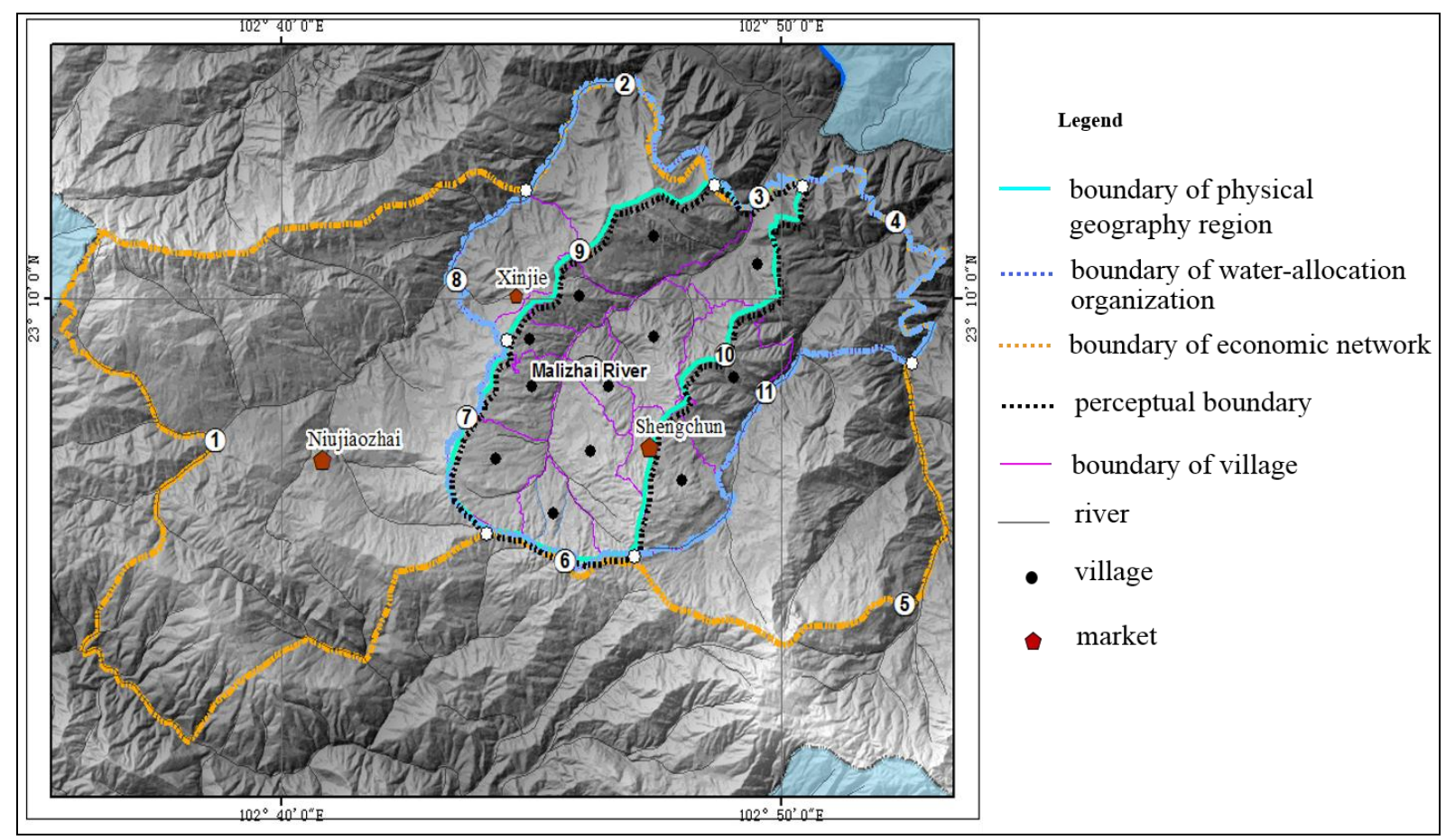

Figure 3. Four boundaries and their overlapping relationship. 


\subsection{Boundary of Economic Network}

The range of an economic network refers to the distance local people sell their farm products and purchase daily items. We interviewed 91 families in the villages of Quanfuzhuang, Malizhai, Tuguozhai and Bajiaoling and all the village leaders in the Malizhai River Basin. They showed us where they sell their products and buy daily necessities or staple goods. The economy of the Hani people relies primarily on traditional rice planting and livestock herding. Their agricultural products are mostly sold locally. According to our interviews, almost all villages within the Malizhai River Basin have adopted this type of economy. There are three important markets that form the economic network and provide severs for this surrounding villages. The market in town of Xinjie, which used to be the county town of Yuanyang County, has the highest level of development compared with other two. Almost all livelihood products can be purchased in this market. Another market, located in the village of Shengcun, once the location of the old township government, is where local residents buy or sell agricultural products for daily goods such as local rice, meat, fruit and vegetables. The last market, located in Niujiaozhai town, is also a former location of the township government. This market is the only livestock-trading market within the area, where local residents purchase livestock mainly for farming and sacrificial activities for major festivals and funerals. These three markets have different functions, and make up a network to support local people's daily life and agricultural production. All villages within Mailizhai River Basin depended on the market network to sell and purchase productions. From an administrative perspective, the market network includes two towns, Niujiaozhai and Xinjie. The administrative boundary of the two towns is the boundary of the economic network of the human-environment system of the Malizhai River Basin (see Figure 3).

\subsection{Perceptual Boundary of Human-Environment System}

The perceptual boundary of a human-environment system was determined by the range of an utilized nature resource and identifying of the kinship and friendship among the villages. The perceptual range of the human-environment system of local residents fits into two categories: The system of "forest, villages, rice terraces and water" and agricultural co-production and water allocation are based on the kinship among villages. A key cultural anthropology study of some villages in the Malizhai River Basin [70] illustrates that the first category of perception includes the spatial perception of the residential boundary, the boundary of the terraced fields and forest that belong to their village and the territory boundary. The interviews of locals also show the kinship in this area. These perceptions are created and enhanced in daily life through two important festivals-Aangmatuo and Kuzhazha-hosted by Migu (the spiritual specialist, authority and core of the village). The main objective of the perceptions is to help the residents use and manage the different types of land. For instance, the villages inhabited by the Hani people are located at mid mountainous areas between the forest in high mountainous areas and the rice terraces in the low area. Each village has clear markings to identity the upper and lower boundaries, which limit the vertical space range of the village. Within the boundary, the climate and environment are suitable for living. More important, living in the range benefits the protection of forest water sources and the allocation and management of agricultural water resources for rice terraces. 
The second category of perception refers to the kinship that supports water-allocation and other agricultural co-production. Another cultural anthropology study that uses a hamlet named Qingkou in the Malizhai River Basin as a case study described the kinships by observing the activities and links between this village and other villages [71]. Qingkou is a Hani village, and its pioneers come from other Hani villages. The frequent contact between Qingkou and the surrounding villages shows that there are two types of relationships between them. One is based on cognatic descent in Hani villages and the other based on co-production between the Hani and other groups. These villages respect and identify with each other and worked together to deal with pressure related to water. In this way, there was less controversy among the kinship villages during the process of water allocation. These two types of relationship exist generally in the villages of the Malizhai River Basin. Besides the evidences in the above literatures, the interview with locals also help us to tell the boundary. Because the villagers' perception is obtained from collective activities, we have not measured the villager's perception of the human-environment system one by one. We only interviewed the Migu and Mupi, Migu are the spiritual specialists of the villages in charge of sacrificing in festival and even the agricultural production. Mupi acts as priest of the village, knows and records the history of his village. There are five Migu and five Mupi were interviewed in Quanfuzhuang, Mailizhai, Zhulu, Shuilongpu and Tuguozhai. All of them emphasized the strong kinship of the Hani villages. Among them, the village with the longest history is the village of Zhulu. The surrounding villages, such as Luopu Large, Luopu Small and Malizhai are all separated from the Zhulu. Quanfuzhuang and some hamlets of Tuguozhai and Shuilongpu are separated from Malizhai. The local Hani people strongly recognize the kinship among villages. This ensures the equitable distribution of water resources among them. In addition, according to the Mupi's values, the Hani people deem Yi and Zhuang people as their brothers with different surnames. In the Malizhai River Basin, the rice terraces of the Hani people are located upstream, and the Yi and Zhuang people's rice terraces are often located downstream, so Hani people allocate water to Yi and Zhuang people. Villages within a watershed thus form an informal group that ensures the equitable distribution of water resources that leads to the group members helping each other during the harvest season. On this basis, the spatial perception of the local residents would be enlarged from a single village to the whole range of relative villages connected by these two types of relationship. Therefore, the range of this kinship villages within the Malizhai River Basin is the perceptual boundary and it almost corresponds to the boundary of the physical geography region (see Figure 3).

\section{Evaluating the Boundary of the Human-Environment System of HHRT}

In order to identify an appropriate boundary for protecting the cultural landscape of HHRT, we need to first analyze the function of the four boundaries based on the evaluation criteria in the methodology framework. The mark "+" indicates the corresponding function of a boundary (see Table 1). For example, there is only one " + " corresponding to the boundary of the physicalgeography region with sustainable development, which means that within the range of this boundary, the sustainable development of the natural environment will be realized because the ecological system of "forest, villages, rice terraces and water system" is encompassed in it. However, this boundary does not reflect social justice or create a new organization for human-environment system. The boundary of water-allocation organization is built based on the Malizhai River Basin and negotiation between twelve 
administration villages, so it guarantees the sustainable development of a natural environment. Moreover, the negotiation between the twelve administration villages is a measure of the social justice present in the villages. Figure 3 shows that the boundary of water-allocation organization is beyond the Malizhai River Basin. This results from the increase in scale occurring the process of water allocation with more villages participating in this organization. In this process, a new organization of local human-environment system was formed among these villages. Therefore, there are three "+" marks that correspond to the boundary of water-allocation organization. The boundary of the economic network was drawn with the three markets as the node, which is located in two important towns. With the development of heritage tourism, the function of these towns is not only to provide a market for selling agricultural products and for local people to purchase necessities, but also to provide services that the heritage area is unable to supply due to restrictions on activities. Xinjie, for example, provides the infrastructure and facilities and support services for heritage tourism. Niujiaozhai is the center for developing and processing traditional agricultural products, and will thus be able to provide more employment opportunities and to attract more local people. From this, we can see that the boundary of the economic network reflects the existing and future construction process of heritage scale, and illustrates the ability of creating a new organization for the local human-environment system. The economic network could not account for both the sustainable development of the natural environment or social justice in the regions, however. The perceptual boundary is consistent with the boundary of the physicalgeography region. Within this range, sustainable development could be assured. In addition, the perceptual boundary is based on the relationship among Hani and Yi villages that are located in the downstream of the same watershed. Social justice between various villages within the perceptual boundary could therefore be assured. The boundary remains within the Malizhai River Basin, however, and does not illustrate the ability of creating a new organization for the local human-environment system by the process of scale constructing.

Table 1. Functions of the boundaries of a human-environment system.

\begin{tabular}{|c|c|c|c|}
\hline \multirow[b]{2}{*}{$\begin{array}{c}\text { Boundaries of } \\
\text { Human-Environment System }\end{array}$} & \multicolumn{3}{|c|}{ Criteria of Evaluating Boundary } \\
\hline & $\begin{array}{c}\text { Environmental } \\
\text { Sustainability }\end{array}$ & Social Justice & $\begin{array}{c}\text { Ability of Creating of } \\
\text { a New Organization }\end{array}$ \\
\hline $\begin{array}{c}\text { Boundary of the physical } \\
\text { geography region }\end{array}$ & + & & \\
\hline $\begin{array}{c}\text { Boundary of water allocation } \\
\text { organization }\end{array}$ & + & + & + \\
\hline Boundary of economic network & & & + \\
\hline $\begin{array}{c}\text { Perception boundary of } \\
\text { human-environment system }\end{array}$ & + & + & \\
\hline
\end{tabular}

After identifying the function of each boundary, we divided them into 11 segments according to their overlapping relationships (see Figure 3) and then evaluated various segments according to the corresponding boundary type and its functions. The mark "+" indicated the functions of a segment (the result is shown in Table 2). For instance, line segment (1) corresponds only with part of the boundary of the economic network. This type of boundary has just one function, that of creating a new organization. Therefore, it is assigned only one "+". Line segment (2) is almost overlapped by parts of the boundary of the economic network and the boundary of water-allocation organization. The boundary of the economic 
network reflects the function of creating a new organization, and the boundary of water-allocation organization outlines the function of supporting sustainable development, assuring social justice and creating a new organization. Therefore, line segment (2) is assigned four "+" marks. Line segment (3) is overlapped by parts of the boundary of the physical geography region, the boundary of water-allocation organization, the boundary of the economic network and the perceptual boundary. This line segment includes all the functions and is assigned seven "+" marks. Line segment (4) represents the overlapping of the boundary of the economic network and the boundary of water-allocation organization. This segment includes the functions of these two boundaries and is assigned four "+" marks. Line segment (5) corresponds only with part of the boundary of the economic network and is thus assigned one "+". Line segment (6) is overlapped by the boundary of the physical geography region, the boundary of water-allocation organization, the boundary of the economic network and the perceptual boundary, and is therefore assigned seven "+" marks. Line segment (7) is overlapped by parts of the boundary of the physicalgeography region, the boundary of water-allocation organization and the perceptual boundary, and so is assigned six "+" marks. Line segment (8) corresponds with only part of the boundary of water-allocation organization and is assigned just three "+" marks. Line segment 9) is overlapped by parts of the boundary of the physicalgeography region and the perceptual boundary, and is assigned three "+" marks. Line segment (10) is overlapped by parts of the boundary of the physicalgeography region and the perceptual boundary and is assigned three "+" marks. Line segment (11) corresponds to part of the boundary of water-allocation organization and acquires three"+" marks. We then ranked the various segments (the results are shown in Table 2). For each segment of boundary, more "+" marks indicates better function. We define the segments with relatively high numbers of "+" marks as constituting the boundary of the World Heritage Site for HHRT. That is to say the closed loop made up of by line sections (3), (6), (7), (2), (4), (11) and (8) is the boundary of area of Malizhai River (see Figure 4). Although line segment (8) and line segment (9) have the same number of "+" marks, we chose line segment (8), because it takes the issue of social justice into consideration more than does segment (9).

Table 2. Boundary-segment scores and rank.

\begin{tabular}{|c|c|c|c|c|c|}
\hline \multirow[b]{2}{*}{$\begin{array}{c}\text { Serial } \\
\text { Number of } \\
\text { Segments }\end{array}$} & \multicolumn{4}{|c|}{ Types of Boundary } & \multirow[b]{2}{*}{$\begin{array}{c}\text { Rank of } \\
\text { Segments }\end{array}$} \\
\hline & $\begin{array}{c}\text { Boundary of The } \\
\text { Physical Geography } \\
\text { Region }\end{array}$ & $\begin{array}{c}\text { Boundary of Water-Allocation } \\
\text { Organization }\end{array}$ & $\begin{array}{c}\text { Boundary of } \\
\text { Economic Network }\end{array}$ & $\begin{array}{l}\text { Perceptual } \\
\text { Boundary }\end{array}$ & \\
\hline (1) & & & + & & 10 \\
\hline (2) & & +++ & + & & 4 \\
\hline (3) & + & +++ & + & ++ & 1 \\
\hline (4) & & +++ & + & & 5 \\
\hline (5) & & & + & & 11 \\
\hline (6) & + & +++ & + & ++ & 2 \\
\hline (7) & + & +++ & & ++ & 3 \\
\hline (8) & & +++ & & & 7 \\
\hline (9) & + & & & ++ & 8 \\
\hline (10) & + & & & ++ & 9 \\
\hline (11) & & +++ & + & & 6 \\
\hline
\end{tabular}


Finally, we compared the new boundary made up of these segments with the existing boundary for the HHRT heritage core area and found that they do not totally overlap. The existing boundary of the heritage core area does not reflect the integrity of the human-environment system in the Malizhai River Basin (see Figure 4). Because we were only analyzing the boundary of human-environment system in the Malizhai River Basin, we evaluated just the portion of the existing boundary for the HHRT heritage core area that overlapped with the human-environment system. As shown in Figure 4, only line segment 7 is overlapped by the existing boundary of the heritage area and the new boundary, and line segment (6) and part of segment (11) were located within the existing heritage area. Most of the segments were located outside of the existing heritage core area. Some entire villages in the downstream areas were not included in the range of the heritage area. Boundaries usually reflect the edges or the periphery of a government's policies, so any differing policies between two sides of a boundary will lead to different results. In the heritage core area, for example, in order to protect the forest, ditches, villages and rice terraces, some protective measures were taken by the local government. With regard to forest protection, entities or individuals are strictly prohibited from removing any wood from forests. With regard to water ditches, the local government is in charge of maintaining the ditches and supervising local residents to protect the water system and management method in the traditional pattern. To protect the rice terraces, the local government encourages traditional farming methods through farming subsidies to maintain the vitality of the water and soil in the rice terraces and prohibit setting fires in the fields, abandoning them or planting dry crops on them $[72,73]$. Under these heritage-protection measures, the human-environment system in the basin will change in different ways. In our field survey, outside the heritage core area, parts of the ditches of some downstream villages were destroyed and abandoned, and villages are increasing planting dry crops instead rice-terraces. These changes will influence the sustainable development of the cultural landscape of HHRT and potentially put its integrity at risk. This should be an important concern in future research.

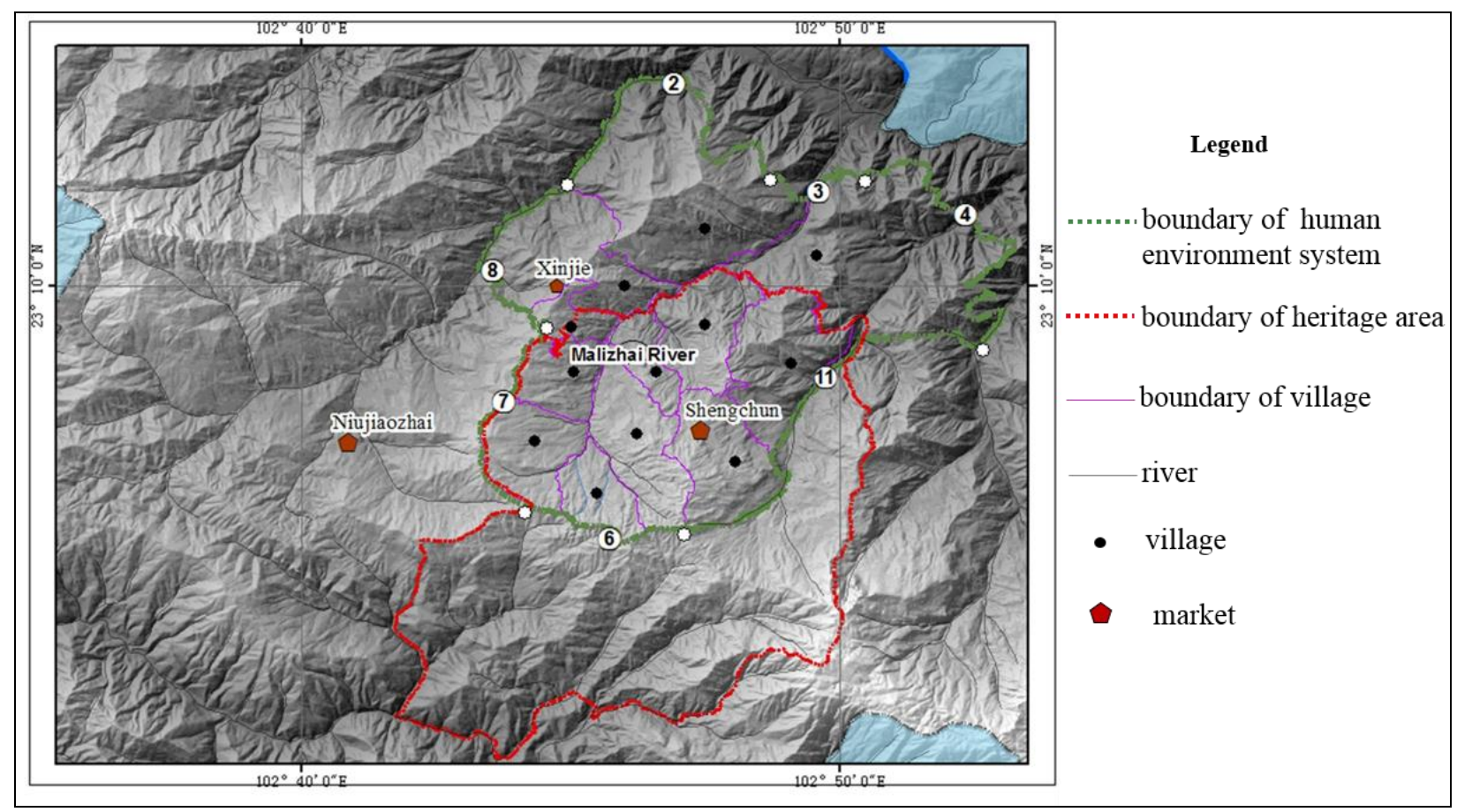

Figure 4. Boundaries of the human-environment system and HHRT heritage area. 


\section{Conclusions}

Our "methodology framework for identifying the boundary of a cultural landscape" provides a holistic perspective and method for determining the boundary of a cultural landscape. The preservation of cultural landscapes that are continually evolving is an important debate in cultural landscape protection. Although some scholars suggest that this dynamic quality sets cultural landscapes apart from the traditional conservation of isolated objects and monuments, there are more complex process and relationships between people and their environment that deserve consideration [74,75]. In most heritage sites, the boundary was still defined simplistically. The "methodology framework" described here emphasizes that the boundary should reflect the complex interactions of people and their environment. Of the four boundary types, the boundary of the physical geography region provides the material basis for economic and social development. The boundary of the economic network reflects the range and scale of economic activities. Within the boundary of social organization, people have equal access to natural resource and healthy economic development. The perceptual boundary reflects conventional wisdom of natural resources and the social network. These four boundary types include the tangible and intangible relationships between people and their environment. Therefore, integrating them into one as a boundary for a cultural landscape can ensure adequate protection.

The case of the HHRT World Heritage Site provides a case study for implementing the methodology framework. In the long-term interactions between the Hani people and the natural environment, they have gradually established a particular human-environment system, which is demonstrated in their relationships with livelihood, social organization, ideology and environment. In the Malizhai River Basin, pressure on land and water resources from the expansion of terraced fields provided the impetus for villages within the watershed to form an informal group that would share water. The watershed contains a whole ecosystem of "forest, villages, rice terraces and water system", providing the material basis for the development of local livelihoods, social organization and perception. The boundary of a watershed is thus fundamental to the protection of rice-terraces landscape. Based on this boundary of the physical geography region, the boundary of water-allocation organization provides the protection mechanism for the sustainable development of the rice terraces landscape. The boundary of the economic network reflects not only local livelihoods and agricultural production, but the support services for heritage tourism and traditional agricultural production, allowing for more opportunities for local people and social vitality. At HHRT, people increasingly migrate outside the area to find their livelihood, and some rice terraces have been abandoned. The same situation occurred at the Rice Terraces of the Philippine Cordilleras World Heritage Site, where the outward migration of the local population was one of the main reasons for the gradual degradation of the rice-terraces [76]. The lessons learned from the Philippine Cordilleras site illustrate the importance of an appropriate economic-network boundary. However, because some economic activities are restricted in the core area, the economic-network boundary can provide a reference for determining the boundary of a buffer zone. The perceptual boundary reflects local knowledge of natural resources and kinship between villages that enable cooperation in agricultural activities. As the basis of water-allocation organization and other social activities, it is key to the intangible aspects of boundaries that support sustainable development of rice terraces landscape. These four boundaries interact in ways that must be accounted for if the HHRT is to be protected. When we integrated the four boundaries into one to evaluate the existing boundary of the 
core area of HHRT, we found that the existing boundary destroyed the integrity of the human-environment system of the Malizhai River Basin. Some parts of the boundary do not fit the criteria of sustainable development. The existing boundary of HHRT World Heritage Site should be redrawn base on three criteria of environmental sustainability, social justice, and ability of creating a new organization.

As discussed above, the methodology framework and case study in this paper provides a reference for determining an appropriate boundary for a cultural landscape based on a holistic perception of the human-environment system. However, the methodology is more suitable for human-environment systems that retain an active social role in contemporary society while being closely associated with a traditional way of life, that display a traditional method of human interaction with the land when this traditional interaction is equally relevant in modern culture. That is, this methodology is fit for delimiting the preserve zone of the "organically evolved landscape".

\section{Acknowledgments}

This research is supported by the Project of NSFC (No. 41271152), the Project of the Humanities \& Social Sciences of the Ministry of Education (13YJCZH053), the Project of Yunnan Philosophy and the Social Sciences (YB2012132). We are very grateful to Matthew Turner and A-Xing Zhu in the Department of Geography at the University of Wisconsin-Madison for their valuable suggestions and Shuangyun Peng and Shihua Li from Yunnan Normal University for their help with the figures. Thanks Rebecca May and Stanley D. Brunn's language polishing and editing.

\section{Author Contributions}

Honglian Hua wrote the major parts of the paper, collected the original sources and data, and created the figures and tables. Shangyi Zhou contributed to the conceptual framework of the methodology and wrote some parts of the article.

\section{Conflicts of Interest}

The authors declare no conflict of interest.

\section{References}

1. Aplin, G. World heritage cultural landscapes. Int. J. Herit. Stud. 2007, 13, 427-446.

2. UNESCO. Operational Guidelines for the Implementation of the World Heritage Convention. July 2013. Available online: http://whc.unesco.org/en/guideline (accessed on 5 August 2014).

3. Gillespie, J. World Heritage management: Boundary-making at Angkor Archaeological Park, Cambodia. J. Environ. Plan. Manag. 2013, 56, 286-304.

4. Gillespie, J. Buffering for conservation at Angkor: Questioning the spatial regulation of a world heritage property. Int. J. Herit. Stud. 2012, 18, 194-208.

5. Taylor, K.; Altenburg, K. Cultural Landscapes in Asia-Pacific: Potential for filling world heritage Gaps. Int. J. Herit. Stud. 2006, 12, 267-282. 
6. Gillespie, J. Protecting world heritage: Regulating ownership and land use at Angkor Archaeological Park, Cambodia. Int. J. Herit. Stud. 2009, 15, 338-354.

7. Gillespie, J. Monumental Challenges: Local Perspectives on World Heritage Landscape Regulation at Angkor Archaeological Park, Cambodia. Ph.D. Thesis, University of Sydney, Sydney, Australia, 2010.

8. UNESCO. Cultural Landscapes: The Challenges of Conservation. 2002. Available online: http://whc.unesco.org/venice2002 (accessed on 30 May 2015).

9. Calderon, M.M.; Bantayan, N.C.; Dizon, J.T. Community-based Mapping of the Rice Terraces Inscribed in the UNESCO World Heritage List. Economy and Environment Program for Southeast Asia. 2009. Available online: http://www.idrc.ca.sci-hub.org/uploads/user-S/12524770881Ifugao_ Final_Report_GIS_component (Marge).pdf (accessed on 29 April 2015).

10. Bantayan, N.C.; Calderon, M.M.; Dizon, J.T. Estimating the extent and damage of the UNESCO World Heritage Sites of the Ifugao. J. Environ. Sci. Manag. 2012, 15, 1-5.

11. Acabado, S. Landscapes and the archaeology of the Ifugao Agricultural Terraces: Establishing antiquity and social organization. Hukay 2014, 15, 31-61.

12. Lu, D.D.; Guo, L.X. Man-earth areal system-the core of geographical study-On the geographical thoughts and academic contributions of academician Wu Chuangjun. Acta Geophys. Sin. 1998, 53, 97-105.

13. Wu, C.J. The core of geographical study-Man-Earth Areal System. Econ. Geogr. 1991, 11, 1-6.

14. Neumann, R.P. Political ecology of wildlife conservation in the Mt. Meru area of Northeast Tanzania. Land. Degrad. Dev. 1992, 3, 85-98.

15. Peluso, N.L. Coercing conservation? The politics of state resource control. Glob. Environ. Change 1993, 6, 199-217.

16. Peluso, N.L. Whose woods are these? Counter-mapping forest territories in Kalimantan, Indonesia. Antipode 1995, 27, 383-406.

17. Manson, S.M. Does scale exist? An epistemological scale continuum for complex human-environment systems. Geoforum 2008, 39, 776-788.

18. Buttimer, A. Landscape and Life: Appropriate scales for sustainable development. Irish Geogr. 1998, 31, 1-33.

19. Buttimer, A. Close to home: Making sustainability work at the local level. Environment 1998, 40, $13-40$.

20. Buttimer, A. Sustainable development: Issues of scale and appropriateness. In Sustainable Landscapes and Lifeways: Scales and Appropriateness, 1st ed.; Buttimer, A., Ed.; Cork University Press: Cork, Ireland, 2001; pp. 24-28.

21. Vallés, M.; Galiana, F.; Bru, R. Towards harmonization in landscape unit delineation: An analysis of Spanish case studies. Landsc. Res. 2013, 38, 329-334.

22. Wiens, J.A. Ecological flows across landscape boundaries: A conceptual overview. In Landscape Boundaries; Hansen, A.J., Ed.; Springer-Verlag Inc.: New York, NY, USA, 1992; pp. 217-235.

23. Ryszkowski, L. Energy and material flows across boundaries in agricultural landscapes. In Landscape Boundaries; Hansen, A.J., Ed.; Springer-Verlag Inc.: New York, NY, USA, 1992; pp. 270-284.

24. O' Reilly, G. Scaling democracy and sustainable development in an Irish context. In Sustainable Landscapes and Lifeways: Scales and Appropriateness, 1st ed.; Buttimer, A., Ed.; Cork University Press: Cork, Ireland, 2001; pp. 287-317. 
25. Lansing, S.; Kremer, J.N. Emergent properties of Balinese water temple networks: Coadaptation on a rugged fitness landscape of Bali. Am. Anthropol. 1993, 95, 97-114.

26. Scarborough, V.I.; Schoenfelder, J.W.; Lansing, J.S. Early statecraft on Bali: The water temple complex and the decentralization of the political economy. Res. Econ. Anthropol. 1999, 20, 299-330.

27. Acabado, S.B. The Archaeology of the Ifugao Agricultural Terraces: Antiquity and Social Organization. Ph.D. Thesis, University of Hawaii, Honolulu, HI, USA, 2010.

28. Chavunduka, C.; Bromley, D.W. Climate, carbon, civil war and flexible boundaries: Sudan's contested landscape. Land Use Policy 2011, 28, 907-916.

29. Swallow, B.M.; Bromley, D.W. Institutions, governance and incentives in common property regimes for African rangelands. Environ. Resour. Econ. 1995, 6, 99-118.

30. Fernandez-Gimenez, M.E. Spatial and social boundaries and the paradox of pastoral land tenure: A case study from post-socialist Mongolia. Hum. Ecol. 2002, 30, 49-78.

31. Beyene, F. Customary tenure and reciprocal grazing arrangements in eastern Ethiopia. Dev. Change 2010, 41, 107-129.

32. Thom, B. The paradox of boundaries in Coast Salish territories. C. Geogr. 2009, 16, 179-205.

33. Wainwright, J.; Bryan, J. Cartography, territory, property: Postcolonial reflections on indigenous counter-mapping in Nicaragua and Belize. C. Geogr. 2009, 16, 153-178.

34. Harris, L.; Hazen, H.D. Power of maps: (Counter) mapping for conservation. Int. J. Crit. Geogr. 2006, 4, 99-130.

35. Hazen, H.D.; Harris, L.M. Limits of territorially-focused conservation: A critical assessment based on cartographic and geographic approaches. Environ. Conserv. 2007, 34, 280-290.

36. Vandergeest, P. Mapping nature: Territorialization of forest rights in Thailand. Soc. Nat. Resour. 1996, 9, 159-175.

37. Vandergeest, P.; Peluso, N.L. Territorialization and state power in Thailand. Theory Soc. 1995, 24, 385-426.

38. Clapp, R.A. Wilderness ethics and political ecology: Remapping the Great Bear Rainforest. Polit. Geogr. 2004, 23, 839-862.

39. Green, T.J. Cultural resource management: Conservation of cultural heritage. In International Encyclopedia of the Social \& Behavioral Sciences; Smelser, N., Baltes, P., Eds.; Elsevier Press: Amsterdam, The Netherlands, 2001; pp. 3113-3116.

40. Sinu, P.A.; Kent, S.M.; Chandrashekara, K. Forest resource use and perception of farmers on conservation of a usufruct forest (Soppinabetta) of Western Ghats, India. Land Use Policy 2012, 29, 702-709.

41. Hayes, T.M.; Murtinho, F. Are indigenous forest reserves sustainable? An analysis of present and future land use trends in Bosawas, Nicaragua. Int. J. Sustain. Dev. World Ecol. 2008, 15, 497-511.

42. Russell, J.; Jambrecina, M. Wilderness and cultural landscapes: Shifting management emphases in the Tasmanian Wilderness World Heritage Area. Aust. Geogr. 2002, 33, 125-139.

43. Woodley, S. Science and protected area management: An ecosystem-based perspective. In National Parks and Protected Areas: Keystones to Conservation and Sustainable Development; Nelson, J.G., Serafin, R., Eds.; Springer: Berlin, Germany, 1997; pp. 11-21.

44. Noss, R.F. Beyond Kyoto: Forest management in a time of rapid climate change. Conserv. Biol. 2001, 15, 578-590. 
45. Schonewald-Cox, C.M.; Bayless, J.W. The boundary model: A geographical analysis of design and conservation of nature reserves. Biol. Conserv. 1986, 38, 305-322.

46. Richards, G. Production and consumption of European cultural tourism. Ann. Tourism Res. 1996, 23, 264-283

47. Loulanski, T. Revising the concept for cultural heritage: The argument for a functional approach. Int. J. C. Prop. 2006, 13, 207-233.

48. Hackenberg, R. Closing the gap between anthropology and public policy: The route through cultural heritage development. Hum. Org. 2002, 61, 288-298.

49. Kelly, P. Globalisation, power and the politics of scale in the Philippines. Geoforum 1997, 28, 151-171.

50. Nielsen, E.; Simonsen, K. Scaling from below: Practices, strategies and urban spaces. Eur. Plan. Stud. 2003, 11, 911-917.

51. Howitt, R. A world in a grain of sand: Towards a reconceptualization of geographical scale. Aust. Geogr. 1993, 24, 33-44.

52. Howitt, R. Scale as relation: Musical metaphors of geographical scale. Area 1998, 30, 49-58.

53. McMaster, R.; Sheppard, E. Introduction: Scale and geographic inquiry. In Scale and Geographic Inquiry: Nature, Society and Method; Sheppard, E., McMaster, R.B., Eds.; Blackwell Publishing Ltd.: Malden, MA, USA, 2008. Available online: http://onlinelibrary.wiley.com/book/10.1002/ 9780470999141 (accessed on 24 January 2015).

54. Ballard, B. Employment and trade in Angkor Park: Some preliminary observations on the impact of tourism. Camb. Dev. Rev. 2003, 7, 5-16.

55. Butland, R. Scaling Angkor: Perceptions of Scale in the Interpretation and Management of Cultural Heritage. Ph.D. Thesis, University of Sydney, Sydney, Australia, 2009.

56. Mao, Y.Q. Analysis on the original name, ethnic origin and migration of Hani people. Yunnan Soc. Sci. 1989, 5, 85-92.

57. Li, Z.X. Water-The origin of life and culture: A discussion of Hani legends and Rrice-farming terrace culture in the Honghe River Valley. In The Collection of Papers of the First International Conference on Hani/AKha Culture; Li, Z.X., Li, Q.B., Eds.; Yunnan Nationality Press: Kunming, China, 1993; pp. 12-25.

58. Compilation Committee of Yuanyang County Chorography. Yuanyang County Chorography; Guizhou Minorities Press: Guiyang, China, 1990; pp. 625-632.

59. Wang, Y. Naturalizing Ethnicity, Culturalizing Landscape: The Politics of World Heritage in China. Ph.D. Thesis, Duke University, Durham, NC, USA, 2008.

60. Ma, T.Z.; Jiang, D.Z.; Li, W.J.; Wang, E.S. The Brief History of Hani; Ethnic Publishing House: Beijing, China, 2008; pp. 6-27.

61. Jiao, Y.M.; Xiao, D.N.; Cheng, G.D. Study on the coordinating development of ethnic culture and natural environment in subtropic mountain areas: A case of cultural landscape of Hani Terrace in Yuanyang County. J. Mt. Sci. 2002, 20, 266-271.

62. Wang, Q.H. The Culture of Terraces; Yunnan University Press: Kunming, China, 1999; pp. 54-77.

63. Jiao, Y.M.; Li, X.Z.; Liang, L.H.; Takeuchi, K.; Okuro, T.; Zhang, D.D.; Sun, L.F. Indigenous ecological knowledge and natural resource management in the cultural landscape of China's Hani Terraces. Ecol. Res. 2012, 27, 247-263. 
64. Yuan, Z.; Lun, F.; He, L.; Cao, Z.; Min, Q.; Bai, Y.; Liu, M.C.; Cheng, S.K.; Li, W.H.; Fuller, A.M. Exploring the state of retention of traditional ecological knowledge in a Hani Rice Terrace village, Southwest China. Sustainability 2014, 6, 4497-4513.

65. James, R.G. Fundamental ecological characteristics of landscape boundaries. In Ecotones, the Role of Landscape Boundaries in the Management and Restoration of Changing Environments; Mariorie, M.H., Paul, G.R., Robert, J.N., Eds.; Chapman and Hall: New York, NY, USA, 1991; pp. 8-30.

66. Monic, A.G.T.; Robert, H.G.; Robert, V.O. Potential responses of landscape boundaries to global environmental change. In Ecotones, the Role of Landscape Boundaries in the Management and Restoration of Changing Environments; Mariorie, M.H., Paul, G.R., Robert, J.N., Eds.; Chapman and Hall: New York, NY, USA, 1991; pp. 52-73.

67. Jiao, Y.; Cheng, G.; Xiao, D. A study on the cultural landscape of Hani's terraces and its protection. Geogr. Res. 2002, 21, 733-741.

68. Huang, S.W.; Liao, G.Q.; Guan, L. The Traditional Eco-cultural Studies on the Yunnan Hani People; China Social Sciences Press: Beijing, China, 2013; pp. 111-116.

69. The Digital Villages of Yunnan. The Digital Village of Yuanyang County, Honghe Prefecture, Yunnan Province. Available online: http://www.ynszxc.gov.cn/S1/S664/S769/ (accessed on 25 October 2014).

70. Luo, D.Y.; Sun, N.; Huo, X. Hani Terrace Villages; China Construction Industry Press: Beijing, China, 2013; pp. 13-85.

71. Ma, Y.W. The Last Mushroom House: The Hani Villager's Diary of Qingkou Village in Xinjie Town in Yuanyang County; China Social Sciences Press: Beijing, China, 2009; pp. 8-65.

72. Legislative Affairs Office of the State Council P. R. China. The Honghe Hani Rice Terraced Protection Regulations of Honghe Hani Autonomous Prefecture, Yunan Province, Standing Committee of Yunnan People's Congress. 31 May 2012. Available online: http://www.chinalaw. gov.cn/article/fgkd/xfg/dfxfg/201211/20121100378258.shtml (accessed on 14 September 2014).

73. The Government of Honghe Prefecture. The Protection and Management Plan of Honghe Hani Rice Terraces (2011-2030); The Government of Honghe Prefecture: Yunnan, China, 2011; pp. 28-30.

74. Alanen, A.; Melnick, R. Introduction: Why cultural landscape preservation? In Preserving Cultural Landscapes in America; Alanen, A., Melnick, R., Eds.; Johns Hopkins University Press: Baltimore, MD, USA, 2000; pp. 1-21.

75. Groth, P.; Wilson, C. The polyphony of cultural landscape study: An introduction. In Everyday America: Cultural Landscape Studies after J.B. Jackson; Groth, P., Wilson, C., Eds.; University of California Press: Berkeley, CA, USA, 2003; pp. 1-22.

76. Dizon, J.T.; Calderon, M.M.; Sajise, A.J.U. Youths' perceptions of and attitudes towards the Ifugao Rice Terraces. J. Environ. Sci. Manag. 2012, 15, 52-58.

(C) 2015 by the authors; licensee MDPI, Basel, Switzerland. This article is an open access article distributed under the terms and conditions of the Creative Commons Attribution license (http://creativecommons.org/licenses/by/4.0/). 